\title{
Variations in the epithelial cords of the ovaries of a microchiropteran bat, Hipposideros speoris (Schneider) during reproductive cycle: An enzymic approach
}

\author{
M. S. Sastry ${ }^{1 \star}$ and S. B. Pillai ${ }^{1}$ \\ ${ }^{1}$ Department of Zoology, Rashtrasant Tukdoji Maharaj Nagpur University, Nagpur University Campus, Nagpur-440033, \\ India. \\ Accepted 11 November, 2013
}

\begin{abstract}
The ovaries of Hipposideros speoris were studied histologically and histochemically for the enzymes, $3 \beta$-hydroxysteriod dehydrogenase (3ß-HSDH), Succinic dehydrogenase (SDH) and lipid from July 2005 to 2006. The interstitial cells or so called "epithelial cords" showed variations in their distribution, morphology, enzymic and their association with other ovarian structures. These cords appear to be formed in the ovarian cortex by the transformation of granulosa of the primordial follicles and small preantral follicles whose ova regress and disappear. Mostly these cords were conspicuous, hypertrophied, abundant and in clusters or in zones occupying a major portion of the cortex during 4 to 5 months of gestation and also during lactation. Both histological and histochemical studies revealed their significance as steroidogenic cells. The frequency with which these structures were observed during pregnancy made it obligatory to conclude that they have a certain significant role in ovarian physiology in overtaking the function of corpus luteum after its regression.
\end{abstract}

Key words: Chiroptera, Hipposideros, ovary, epithelial cords.

\section{INTRODUCTION}

Interstitial gland cells constitute an important ovarian component with steroidogenic function. The ovaries of Hipposideros speoris showed occurrence of three types of interstitial gland cells (Igc) - the thecal type Interstitial cells, stromal type Interstitial cells and epithelial cords (EC), all showing cyclical alterations histologically and histochemically with the reproductive cycle. These EC appear to be formed in the ovarian cortex either by the invagination of the germinal epithelium or by the transformation of granulosa cells of primordial follicles and small preantral follicles whose ova regress and disappear (Pillai, 2004). The existences of epithelial cords were documented among a variety of mammalian species (MacLeod, 1880; Matthews, 1935; Barker, 1951; Dawson and McCabe, 1951; Rennels, 1951; Brambell, 1956; Guraya and Greenwald, 1964a, 1964b, 1965; Guraya, 1968; Mori and Matsumoto, 1970; Motta, 1974; Guraya, 1985, 2000) including a single chiropteran species, Myotis grisescens (Guraya, 1967c). The present study gives an account of EC during the complete reproductive cycle. Such observations may help in understanding the functional significance of EC in the cycling ovaries.

\section{MATERIALS AND METHODS}

Specimens of $H$. speoris were collected twice every calender month throughout the year with the help of a mist net from the natural population inhabiting abandoned mines in Khapa, Nagpur, Maharashtra. For histological studies, the ovaries were fixed quickly in Bouin's fixative, dehydrated in ethanol and embedded in paraffin 

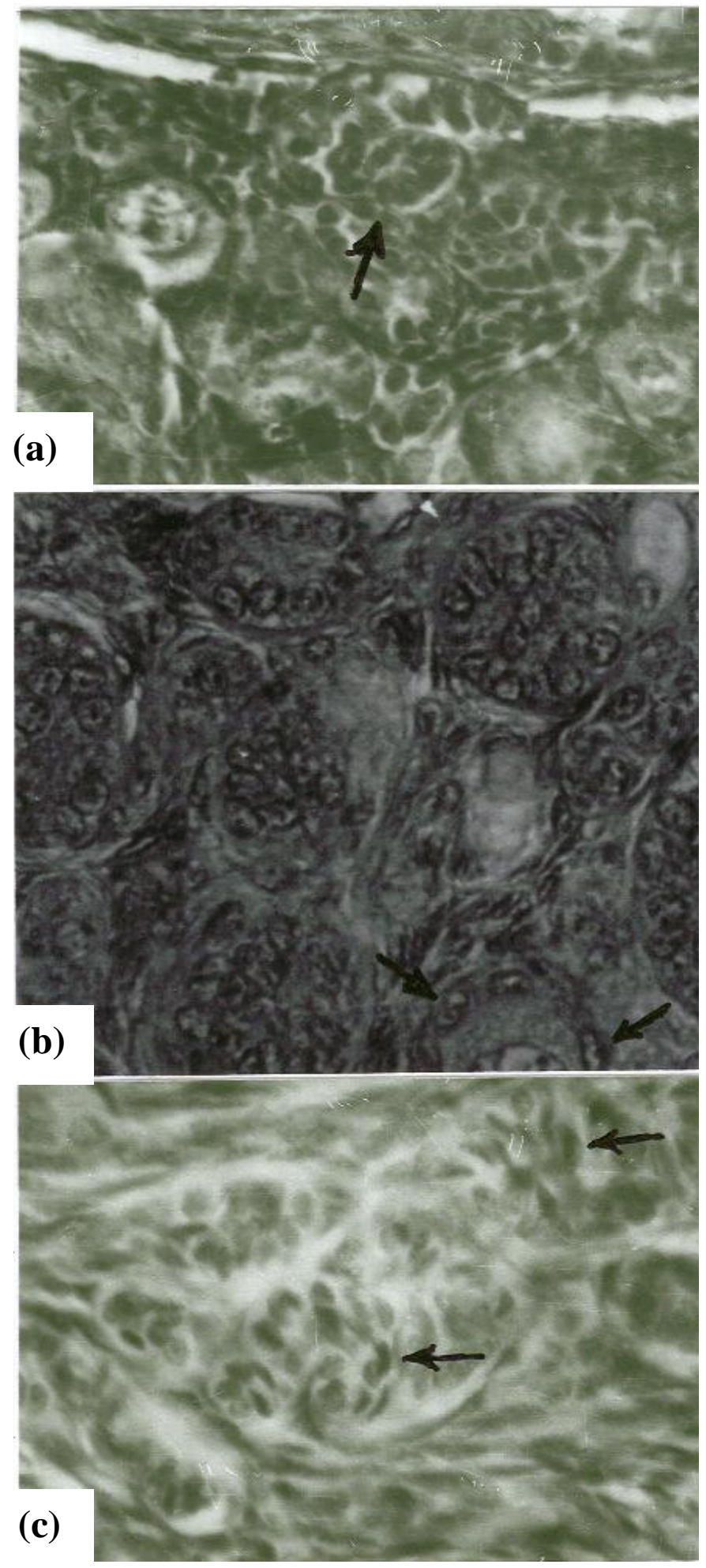

Figure 1. (a) Magnified view of the ovarian cortex clearly demonstrating the formation of epithelial cords by sinking of germinal epithelial nodules (arrow). (b) Cortical region magnified to show formation of epithelial cords from the degenerating primordial follicles by the hypertrophy of preganulosa cells (arrow). (c) Magnified view of the deep cortical part showing the epithelial cord formation from the remnants of atretic small primary follicles (arrow) X 250 . wax. The sections cut at $5 \mu \mathrm{m}$ were stained with haematoxylin and eosin.

For histochemical studies, calcium-formal and buffered formalin fixed and unfixed frozen tissues were cut on freezing microtome at $20^{\circ} \mathrm{C}$ and stored at $-25^{\circ} \mathrm{C}$ until stained (Pearse, 1972; Lillie and Fullmer, 1976).

Lipids appeared black or bluish black when cut frozen sections were washed in water for 2 to $5 \mathrm{~min}$ to remove formaldehyde, dehydrated for 3 to $5 \mathrm{~min}$ in pure propylene glycol by moving sections at intervals, transferred to the dye solution $(0.7 \mathrm{~g}$ of Sudan black $\mathrm{B}$ dissolved in $100 \mathrm{ml}$ propylene glycol at 100 to $110^{\circ} \mathrm{C}$ ) for 3 to $7 \mathrm{~min}$ with occasional agitation. Then differentiated in $85 \%$ propylene glycol for 2 to $3 \mathrm{~min}$ and washed in glycerol jelly.

For the determination of $3 \beta-\mathrm{HSDH}$ fresh frozen cryostat sections were incubated aerobically at $37^{\circ} \mathrm{C}$ in incubation medium containing dimethyl formamide (DMF); $\beta$-Nicotinamide Adenine Dinucleotide $(\beta-N A D)$; Nitro blue tetrazolium salt (NBT) and pregnenolone for 30 to $45 \mathrm{~min}$ Then post fixation of sections were done by $10 \% \mathrm{~N}$ formalin for $10 \mathrm{~min}$, washed and rinsed in DMF. Again washed in water and mounted in glycerol jelly.

Acetone fixed cryostat sections were employed for SDH localization. Sections were incubated in a medium consisting of Nitroblue tetrazolium salt in $0.1 \mathrm{M}$ phosphate buffer $(\mathrm{pH}=7.6)$, and sodium succinate at $37^{\circ} \mathrm{C}$ for 10 to 30 min washed, dehydrated in series of alcohols, cleared and mounted in permount.

\section{RESULTS}

$H$. speoris is a monovular and monotocous bat, breeding once in a year from December to May and the gestation lasts for $135 \pm 5$ days starting from second week of December upto last week of April.

The EC were encountered throughout the reproductive cycle but a variation in their distribution, morphology, enzymity and their association with other ovarian structures were observed. They were found to have originated either by the invagination of the germinal epithelium or from the hypertrophy of persistent granulosa of atretic primordial and small preantral follicles (Figure $1 \mathrm{a}, \mathrm{b}$ and C). Each cord consisted of a single layer of either spherical or ovoid epithelial cells with vesicular nuclei lined by basement membrane.

During anoestrous, proestrous and estrus (July to November) the EC were mostly individual, few in number, small in size and irregularly distributed among the primordial follicles (Figure 2a, b, c). The cords showed less accumulation of lipid droplets and low to negligible enzyme activity.

A sudden spurt in development was observed at the approach of pregnancy. The early gestation was thus marked by EC scattered in the cortex either in groups of 2 to 3 or singly. Each cord consisted of few small cells with vesicular nuclei (Figure 2e). Early pregnancy was marked by an extrovert functional corpus luteum which was fully functional. The cords were sudanophilic with fine lipid droplets aggregated along the cells borders (Figure 2f), similarly, the cords exhibited moderate $3 \beta$ $\mathrm{HSDH}$ activity concentrated particularly along the borders of the cells (Figure 2g). The histochemical distribution of $\mathrm{SDH}$ was low to moderate (Figure $2 \mathrm{~h}$ ). 

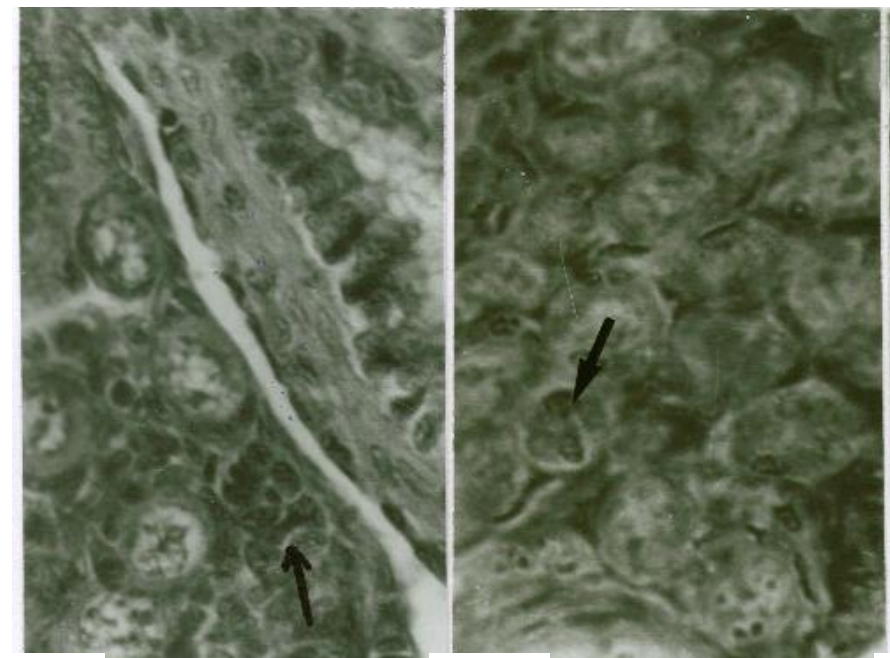

(a)

(b)
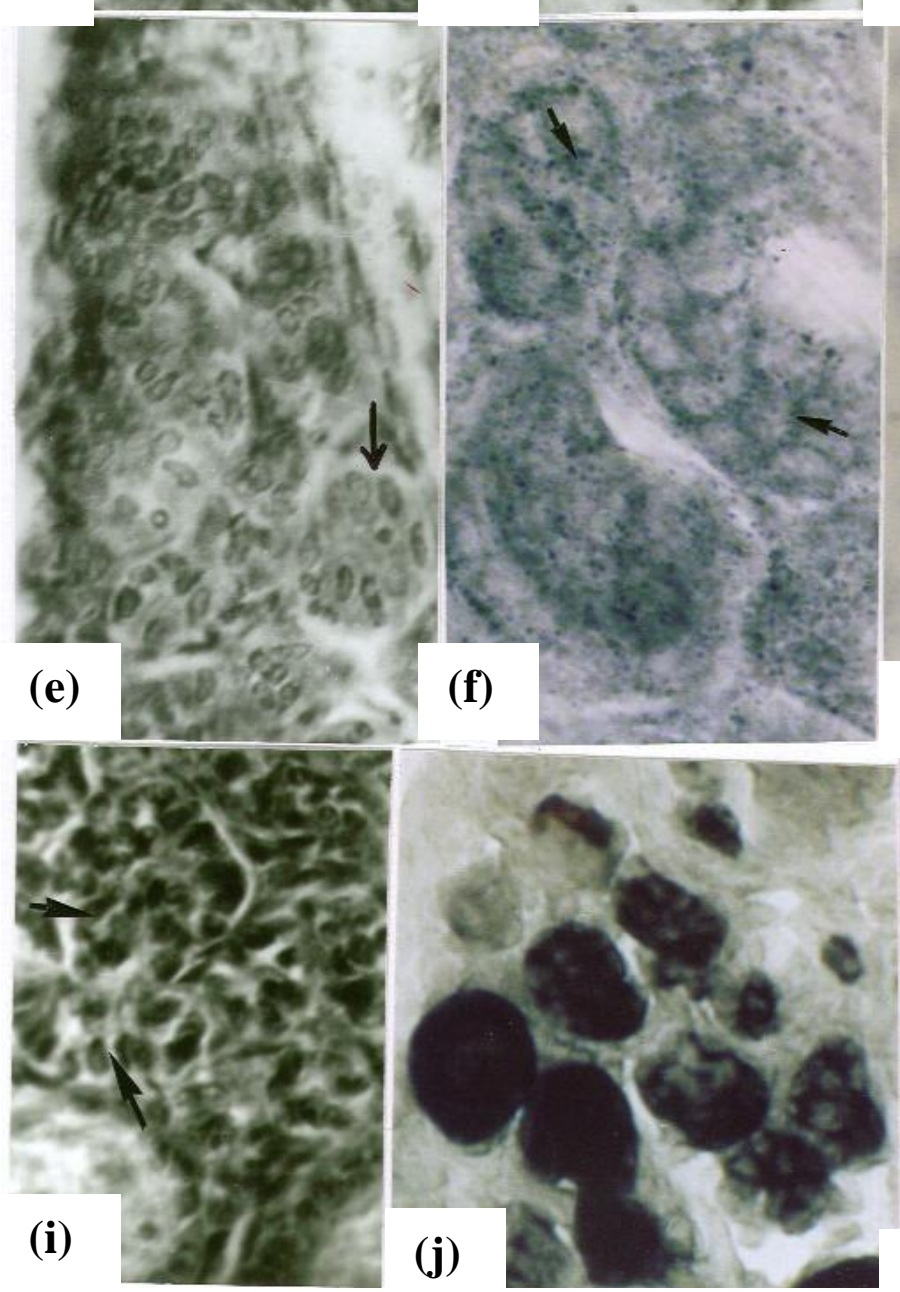

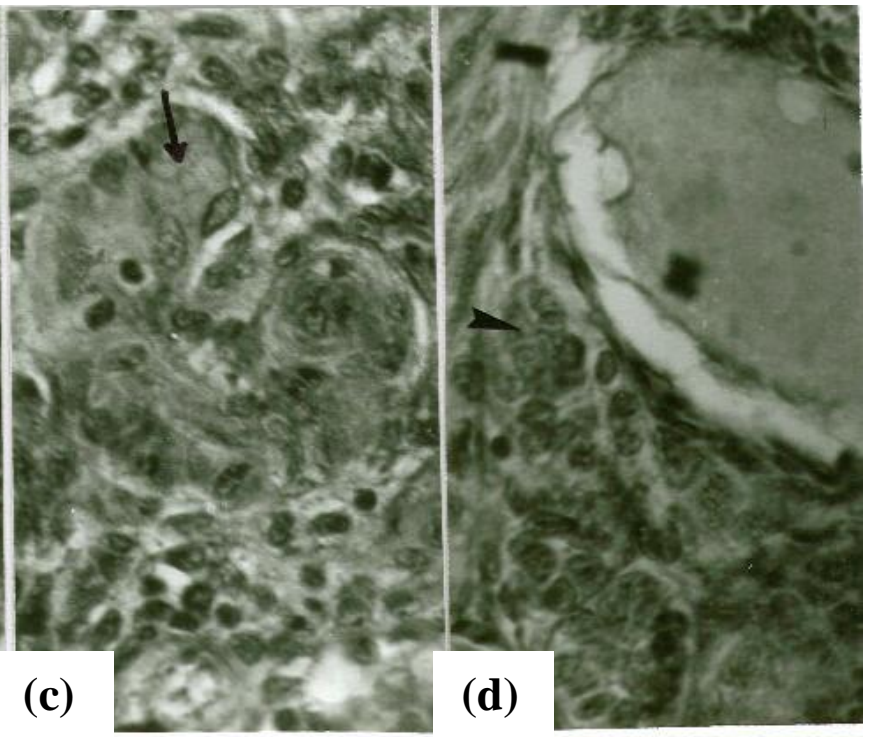

(c)
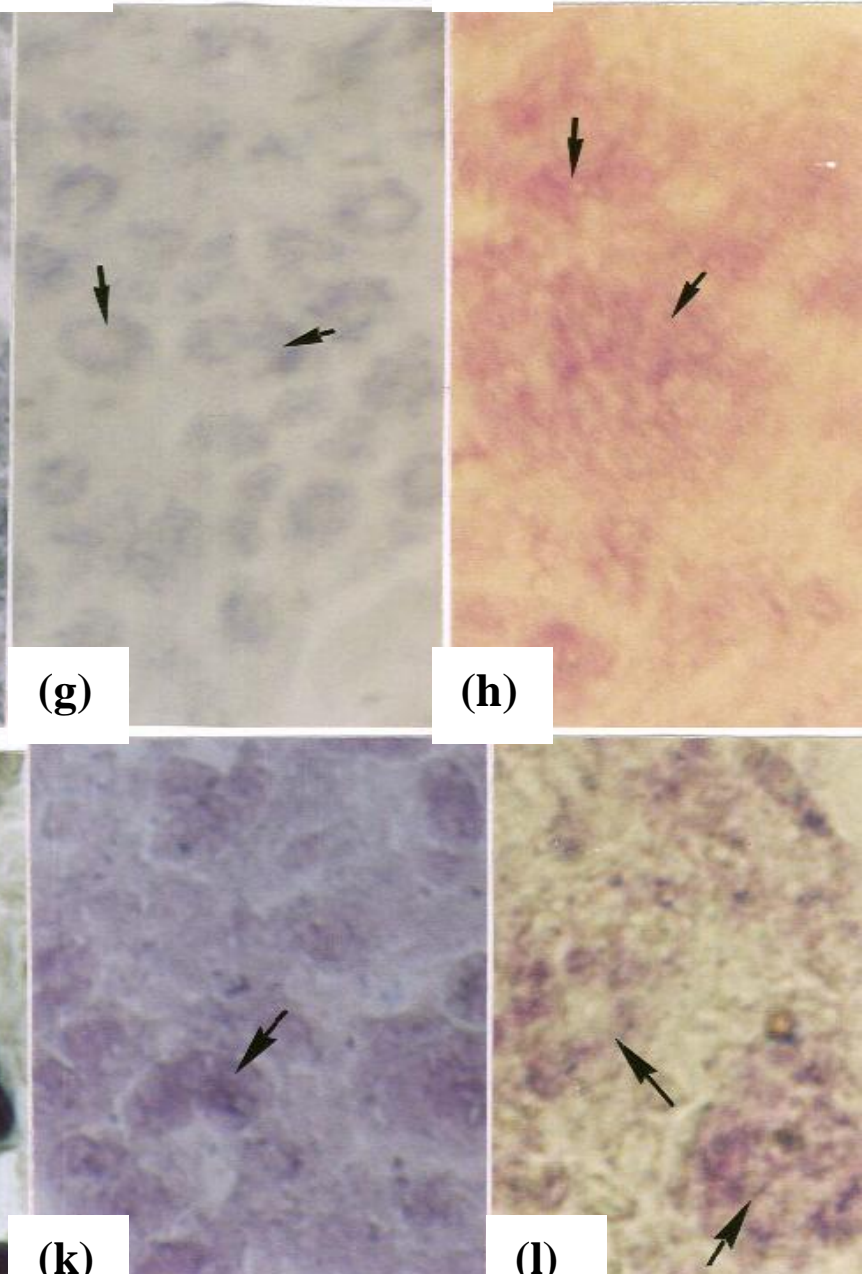

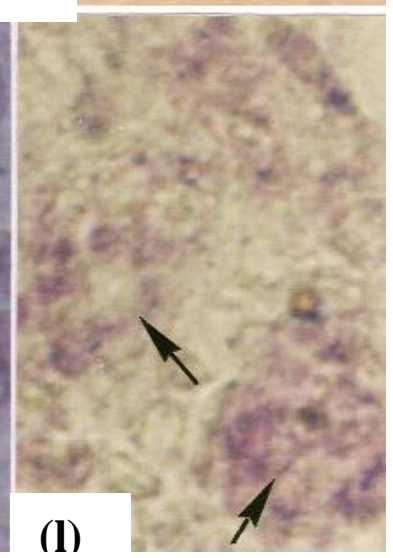

Figure 2. (a) Epithelial cords (arrow) distributed individually between primordial follicles at anoestrous. (b) Reduced but well-defined epithelial cords (arrow) at proestrus. (c) Arrow marks the regressed epithelial cords, with inactive cells during estrus phase (d) Epithelial cords during mid pregnancy shifted towards medullary region in the vicinity of blood capillary (arrow head). (e) Epithelial cords during early pregnancy scattered in cortical region either in groups of 2 - 3 or singly. Note the smaller size of the cords with few cells in each cord (arrow). (f) Aggregation of epithelial cords during early pregnancy demonstrating diffuse lipid droplets along the cell outlines (arrow). (g) Epithelial cords at early pregnancy exhibiting moderate $3 \beta-\mathrm{HSDH}$ activities (arrow). (h) Epithelial cords (arrow) from early pregnancy illustrating moderate SDH activity. (i) A cluster of highly hypertrophied and active epithelial cords (arrow) consisting of $20-30$ cells X 250. (j) Well developed epithelial cords intensely stained with Sudan black B (k) moderate to strong $3 \beta$-HSDH activities in the epithelial cords along cell borders (arrow) during early pregnancy. (I) Epithelial cords (arrow) during early pregnancy showing moderate SDH activity X 250. 
At neural groove stage of embryo development (early February) the newly formed placenta and the corpus leuteum both were functional and the EC were extensive, highly hypertrophied large in size, coiled, clustered, each cord was demarcated by separate basal lamina and was lined by a single layer of 20 to 30 cells (Figure 2i). More often the cords get shifted towards the cortico-medullary region and mostly found in the vicinity of capillary loops. The cords displayed accumulation of diffuse sudanophilic lipid droplets (Figure 2j) and demonstrated intense steroidogenic activity (Figure $2 \mathrm{k}$ ) but $\mathrm{SDH}$ activity was moderate (Figure 2l).

The EC were at their peak of development, more or less occupying the complete peripheral cortex, were distributed into zones, each showing presence of highly hypertrophied 30 to 40 cells at the limb-bud stage of embryonic development during March (Figure 3a) when the placenta was functional but the corpus luteum was regressed. Many of them were in medullary region in close association with the capillary loops (Figure 2d). The cords histochemically exhibited rich sudanophilic lipid droplets (Figure $3 \mathrm{~b}$ ), marked $3 \beta-\mathrm{HSDH}$ and $\mathrm{SDH}$ activities (Figure $3 c$ and d).

During the near term period, that is late April-Early May, the EC were restricted only to some peripheral cortical portions. There was a decline in their number and appeared inactive. Even there was a reduction in the size of clusters; now only 2 to 3 cords formed a cluster, which was previously observed to be 10 to 12 . The cells of each cord were also reduced in size and numbers when the placenta was well established (Figure $3 e$ ) but the corpus luteum was completely absorbed. The cords revealed large clumps of lipids of coarse nature (Figure 3f), faint $3 \beta$-HSDH activity (Figure $3 g$ ) and SDH activities (Figure $3 \mathrm{~h}$ ).

However, during lactation (May), there was a pick up in the activities of EC showing an increase in cord number and size with 15 to 30 hypertrophied vesicular cells in each cord (Figure 3i) but some ovaries showed contrast activities of epithelial cords, as there is an asynchrony in the reproductive cycle from the same period. Histochemically the cords demonstrated abundant diffuse sudanophilic lipid droplets (Figure 3j), enhanced activities of $3 \beta \mathrm{HSDH}$ (Figure 3k) and marked activity of SDH (Figure 3l).

\section{DISCUSSION}

The origin of these structures remains controversial. They were believed to be originating either by the invagination of the germinal epithelium (Simpson and Van Wagenen, 1953; Guraya and Greenwald, 1964a, 1964b; Motta, 1974) or from the hypertrophy of granulosa cells of the primordial follicles and small preantral follicles, whose ova were lost by atresia (Guraya, 1967a, 1968a, b, d). In H. speoris the origin of epithelial cords were observed to be of dual nature that is, from the germinal epithelium by its in growth and from the persisting granulosa of atretic primordial follicles and small preantral follicles.
In the present study, cyclic changes in the epithelial cords are related with the reproductive cycle of $H$. speoris. Thus, during early pregnancy, the EC were found scattered in the cortex either in groups of 2 to 3 or singly. But during mid-pregnancy, there was a sudden burst in the histological and histochemical activities. These activities were more enhanced during advanced pregnancy as evident by the occurrence of densely populated, highly hypertrophied zones in the cortex, may be equivalent structures to - accessory corpora lutea, supporting the chorio-allantoic placenta to sustain the development of the embryo. Also during the lactation, the cords were abundant and histochemically functional, might be for the synthesis of hormones, progesterone and estrogen necessary for the synthesis and secretion of milk. The EC during proestrus and estrus were mostly individual and irregularly distributed, this insignificance in their development might be due to the development of the thecal lgc only during proestrus and estrus, thus, subsiding the preexisting progesterone secreting EC which were important in the implantation of the blastocyst, its further development and the pro-gestational changes undergone by the uterus (Pillai, 2004).

Lipids are the precursors for steroid biosynthesis and its accumulation in the tissues suggests hormone storage and the amount decreases when hormone gets released (Guraya, 1985). Similarly, the enzyme $3 \beta-\mathrm{HSDH}$ is associated with the microsomes derived from extensively developed granular endoplasmic reticulum, whose function in the cell is conversion of pregnenolone to progesterone (Kovarik and Velardo, 1979). Thus, highly sudanophilic and $3 \beta-H S D H$ positive cords suggest their role in steroid biosynthesis as earlier discussed (Baker, 1951; Guraya and Greenwald 1964a; Guraya, 1985, 2000). As the EC shift towards the medullary parts develop the histochemical features specific to steroid secreting cells, which consists of the presence of diffusely distributed sudanophilic lipid droplets (Guraya, 2000; Guraya and Motta, 1980). The shifting of EC to the medullary region and association with the blood capillaries also suggested their role in the metabolism of steroidal compounds particularly progestins (Savard et al., 1965; Guraya, 1985).

Though the activity of SDH is used as a criterion of luteal function, its activity is correlated with presumed sites of hormone production and places of cellular proliferation (Meyer et al., 1945, 1947). The EC exhibited conspicuous SDH reactivity being highest during midpregnancy and lactation as observed in rabbit (Foraker et al., 1955).

The fate of the cord could not be determined, however, from the foregoing study the epithelial cords were observed to be degenerating and finally reverting back to the stromal tissue.

\section{Conclusion}

The ovary of $H$. speoris shows extensive development of 

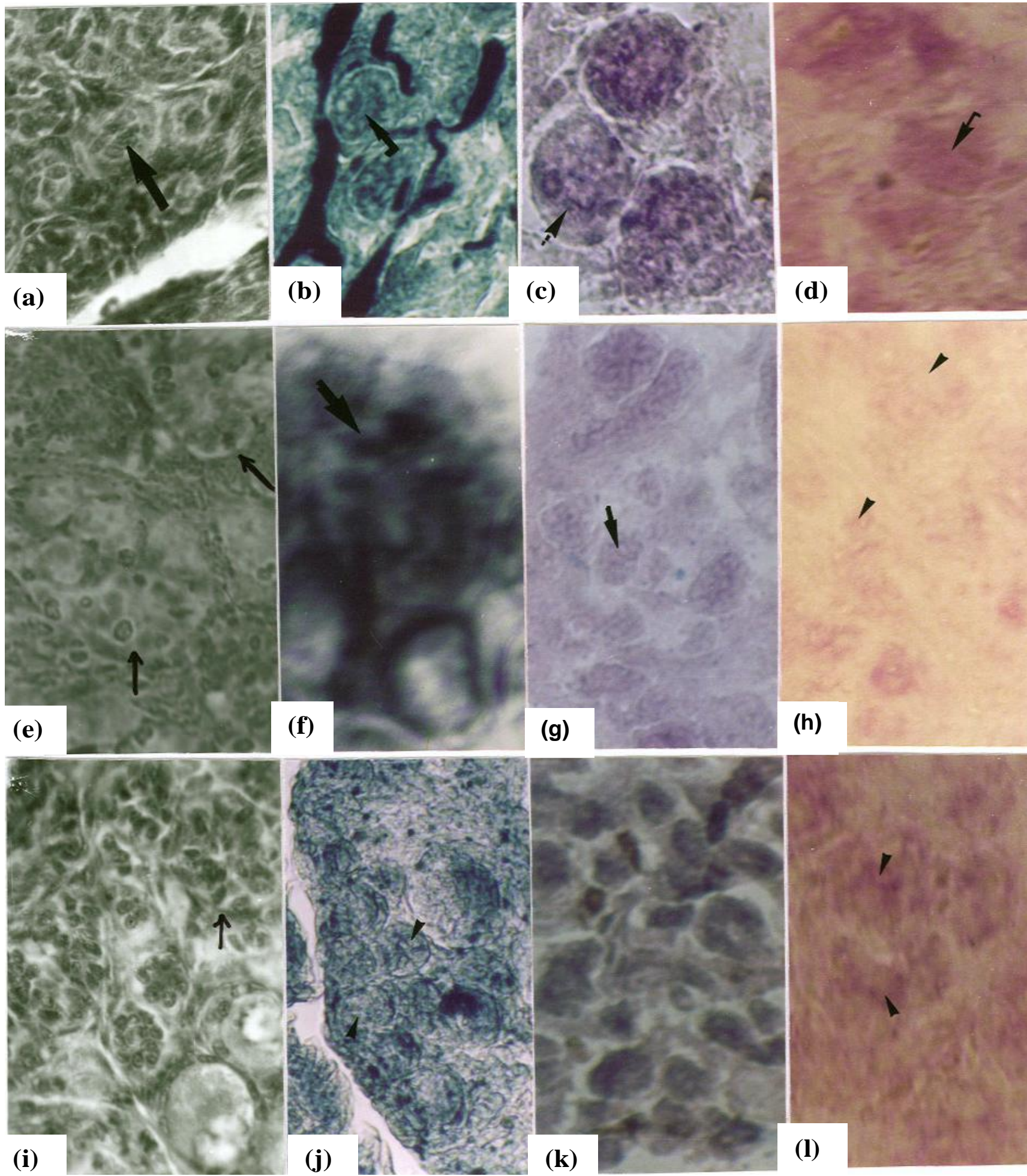

Figure 3. (a) Highly hypertrophied, closely clustered cortical zones of epithelial cords, each with $20-30$ hypertrophied cells in each cord (arrow). (b) Dense accumulation of sudonophilic lipids in the cords (arrow). (c) An abrupt shoot up in the 3ß-HSDH reactivity in highly developed epithelial cords (arrow). (d) Closely packed intense SDH granules giving a diffused pattern of distribution in the epithelial cord (arrow). (e) The reduction in the size of cluster with degenerating cells (arrow). (f) Reduced number of epithelial cords revealing large clumps of lipid droplets of coarse nature (arrow). (g) Epithelial cords (arrow), exhibiting very faint $3 \beta$ - $\mathrm{HSDH}$ reaction. (h) Faint SDH reactivity in the ill-developed epithelial cords (arrow). (i) An increase in size and number of epithelial cords with vesicular cells (arrow). (j) Epithelial cords in the cortical region showing abundant diffuse sudanophilic lipid droplets. (k) On enhanced $3 \beta-\mathrm{HSDH}$ reactivity in well-developed epithelial cords. (I) Few epithelial cords (arrow) demonstrating high to moderate SDH activity X 250. 
epithelial cords particularly during mid and advanced pregnancy and lactational. These EC present wide variations in morphology and histochemistry throughout the reproductive cycle. Both morphological and the histochemical studies revealed their significance as steroidogenic cells in $H$. speoris. The frequency with which these structures were observed during late stages of pregnancy and lactation made it obligatory to conclude that they have a certain significant role in ovarian physiology.

\section{REFERENCES}

Barker WL (1951). A cytological study of lipids in sow's ovaries during the estrous cycle. J. Endocrinol. 48: 772-785.

Brambell FWR (1956). Ovarian changes. In Marshall's Physiology of Reproduction. Ed. A. S. Parkes Vol-I Longmans Green and Co. London. pp. 397-542.

Dawson AB, McCABE M (1951). The interstitial tissue of the ovary in infantile and juvenile rats. J. Anat. 88: 543-571.

Foraker AG, Denham SW, Mitchell DD (1955). Succinic dehydrogenase and endogenous reductase activity in the rabbit ovary in pregnancy. J. Obstet. Gynaecol. Br. Emp. 62: 447-451.

Guraya SS (1967a). Cytochemical observations concerning the formation, release and transport of lipid secretary products in the interstitial (thecal) cells of the rabbit ovary. Zeitschrift fur Zellforschung 83: 187-195.

Guraya SS (1967c). Cytochemical study of interstitial cells in the bat ovary. Nature (London). 214: 614-616.

Guraya SS (1968). Histophysiology and histochemistry of interstitial gland tissue in the ovaries of non-pregnant marmosets. Acta Anatomica (Basal) 70: 623-640.

Guraya SS (1968a). Histochemical study of interstitial cells in the cattle ovary. Acta Anatomica 70: 447-458.

Guraya SS (1968b). Comparative observations on the origin and function of epithelial cords in the mammalian ovary. VI Congress for International Reproduction \& Animals Inseminated Artificially, Paris. $1: 141-143$.

Guraya SS (1968d). A histochemical study of preovulatory and postovulatory follicles in the rabbit ovary. J. Reprod. Fertil. $15: 381-387$.

Guraya SS (1985). Biology of ovarian follicles in mammals. SpringerVerlag (Heidelberg- Berlin, New York).

Guraya SS (2000). Comparative cellular and Molecular biology of ovary in mammal: Fundamental \& applied aspects. Oxford and IBH publishing Co. Pvt. Ltd. New Delhi.

Guraya SS, Greenwald GS (1964a). Histochemical studies on the interstitial gland in the rabbit ovary. Am. J. Anat. 114: 495-519.

Guraya SS, Greenwald GS (1964b). A comparative histochemical study of interstitial tissue and follicular atresia in mammalian ovary. Anat. Rec. $149:$ 411-434.

Guraya SS, Greenwald GS (1965). A histochemical study of the hamster ovary. Am. J. Anat. 116: 257-268.
Guraya SS, Motta PM (1980). Interstitial cells and related structure. In : Biology of the ovary. (Eds.) P.M. Motta and E.S.E. Hafez, Martinus Nijhoff, London. pp. 66-85.

Kovarik FA, Velardo JT (1979). Histochemical study of ovarian hydroxysteroid dehydrogenase activity during normal pseudopregnancy in the rat. Anat. Rec. 194: 273-282.

Lillie RD, Fullmer MH (1976). Histopathologic technique and practical histochemistry. IV Edition, J. D. Jeffers \& Anne, T. Vinnicombe (Eds.) McGraw-Hill Inc. U.S.A. p. 568.

Macleod MJ (1880). Contribution a l'etude de la structure de l'ovaire des Mammiferes. Arch. Biol. 1: 241-278.

Matthews LH (1935). The oestrous cycle and intersexuality in the female mole (Talpa europaea). Proc. Zool. Soc. London 39: 347-383.

Meyer RK, McShan WH, Erway WF (1945). Succinic dehydrogenase activity of ovarian and luteal tissue. Endocrinology 37: 431-436.

Meyer RK, Soukup SW, McShah WH, Biddulp C (1947). Succinic dehydrogenase in rat ovarian tissues during pregnancy and lactation. Endocrinology 41: 35-44.

Mori H, Matsumoto K (1970). On the histogenesis of the ovarian interstitial gland in rabbits. I Primary interstitial gland. Am. J. Anat. $129: 289-306$

Motta $P$ (1974). The fine structure of the ovarian cortical crypts and cords in mature rabbits. Acta Anatomica 90: 36-64.

Pearse AGE (1972). Histochemistry theoretical and applied. $3^{\text {rd }}$ Edition (Vol. 2) Churchill Livingston.

Pillai SB (2004). Histo-Enzymological Changes In The Ovary Of A Microchiropteran Bat Hipposideros Speoris (Schneider) During Reproductive Cycle. Ph.D. Thesis, Nagpur University, Nagpur.

Rennels EG (1951). Influence of hormones on the histochemistry of ovarian interstitial tissue in the immature rat. Am. J. Anat. 88: 63-108.

Savard K, Marsh JM, Rice F (1965). Gonadotropins and ovarian steroidogenesis. Recent Prog. Horm. Res. 21:285-365.

Simpson ME, Van Wagenen G (1953). Response of the ovary of the monkey (Macaca mulatta) to the administration of the pituitary follicle stimulating hormone (FSH). Anat. Rec. 115: 570. 